\section{REPRESENTAÇÕES DE QUALIDADE DE VIDA NO TRABALHO EM UMA AGÊNCIA REGULADORA BRASILEIRA $^{1}$}

\author{
Quality of Life Representations at Work on a Brazilian \\ Regulatory Agency
}

\section{Representaciones de Calidad de Vida en el Trabajo en una Agencia Reguladora Brasileña}

\section{Représentations de Qualité de Vie au Travail dans une Agence Régulatrice Brésilienne}

\section{Resumo}

O objetivo desta pesquisa foi identificar as representações de trabalhadores de uma agência reguladora brasileira acerca da qualidade de vida no trabalho e das fontes de bem-estar e mal-estar no trabalho. A pesquisa foi baseada no referencial teórico da Ergonomia da Atividade Aplicada à Qualidade de Vida no Trabalho - EAA_QVT. Participaram 1.945 trabalhadores, o que corresponde a $63,01 \%$ do coletivo de trabalhadores da agência no momento do estudo. Utilizou-se a versão eletrônica do Inventário de Avaliação de Qualidade de Vida no Trabalho - IA_QVT como instrumento. Os resultados indicam que a qualidade de vida no trabalho na visão dos participantes da pesquisa diz respeito a corpo gerencial capacitado, oportunidades iguais de capacitação, ambiente de trabalho saudável, satisfação com o trabalho, equilíbrio entre saúde, produtividade e vida social, trabalho como fonte de realização e prazer, e ambiente cooperativo entre colegas e espaço de fala. Como fontes de bem-estar no trabalho, os trabalhadores relataram o sentimento de gostar das atividades que se realiza, a possibilidade de crescimento profissional, a prerrogativa de terem tempo para tratar de assuntos relacionados à vida pessoal, a satisfação de prestar serviços de qualidade à sociedade, as relações socioprofissionais harmoniosas tanto com os colegas como com as chefias imediatas, o sentimento de dever cumprido e o espaço existente de liberdade de ação, as condições de trabalho adequadas, a remuneração satisfatória e a flexibilidade de horário. As principais fontes de mal-estar no trabalho no contexto da agência reguladora foram o despreparo e arrogância gerencial, ingerência, clientelismo e a ocupação de cargos comissionados por pessoas não concursadas, interação conflituosa com usuários, precariedade dos trabalhadores terceirizados, excesso de burocracia, falta de planejamento, execução de tarefas repetitivas e condições de trabalho precárias. Os resultados são discutidos à luz da literatura no campo das ciências do trabalho e da EAA_QVT.

Palavras-chave: qualidade de vida no trabalho; ergonomia da atividade; bem-estar no trabalho; mal-estar no trabalho; agência reguladora brasileira.

\section{Abstract}

This research aimed to identify the representations of employees of a Brazilian regulatory agency about the quality of working life and welfare and malaise sources at work. The

\section{Artigo Original}

1) Administradora pelo Centro Universitário de Brasília. Mestre em Psicologia Social, do Trabalho e das Organizações (PPGPSTO, UnB). Doutoranda em Psicologia Social, do Trabalho e das Organizações (PPG-PSTO, UnB).

2) Psicólogo do trabalho, Doutor pela École Pratique des Hautes Études (EPHE, França), com pós-doutorado Université Paris 1 Sorbonne (França) em Ergonomia da Atividade Aplicada à Qualidade de Vida no Trabalho. Professor associado 2 no Departamento de Psicologia Social e do Trabalho do Instituto de Psicologia da Universidade de Brasília (UnB) e no Programa de Pós-Graduação em Psicologia Social, do Trabalho e das Organizações (PPG-PSTO) do Instituto de Psicologia.

3) Doutora em Psicologia Social, do Trabalho e das Organizações (PPG-PSTO, UnB). Professora Adjunta no Instituto de Psicologia, Universidade de Brasília.

4) Mestre em Psicologia Social, do Trabalho e das Organizações (PPG-PSTO, UnB). Psicóloga pela Universidade de Brasília. 
research was based on the theoretical framework of Ergonomics Applied Activity on Quality of Life at Work - EAA_QVT. 1,945 workers participated, corresponding to $63.01 \%$ of the agency workers collective at the time of the study. The electronic version of the Inventory of Quality of Life Assessment at Work - IA_QVT was used as a tool. The results indicate that the quality of working life according to the participants' view is a skilled management team, equal opportunities of training, healthy work environment, job satisfaction, balance between health, productivity and social life, work as a source of accomplishment and pleasure, and cooperative atmosphere between colleagues and speaking space. As sources of well-being at work, workers reported they like the activities they do, the possibility of professional growth, the prerogative of having time to deal with personal life issues, satisfaction of providing quality services to society, harmonious social and professional relationships both with colleagues and with the immediate supervisors, the feeling of accomplishment and the space to work freeely, appropriate working conditions, satisfactory payment and flexible hours. The main sources of discomfort at work in the context of the regulatory agency were the management lack of preparation and arrogance, mismanagement, clientelism and the occupation of commissioned positions by non contested, conflictual interaction with users, precariousness of outsourced workers, excessive bureaucracy, lack of planning, execution of repetitive tasks and precarious working conditions. The results are discussed in light of literature in the field of labor sciences and EAA_QVT.

Keywords: quality of life at work; activity ergonomics; well-being at work; malaise at work; brazilian regulator agency.

\section{Resumen}

El objetivo de este trabajo fue identificar las representaciones de trabajadores de una agencia reguladora brasileña acerca de la calidad de vida en el trabajo y de las fuentes de bienestar y malestar en el trabajo. La investigación fue basada en el referencial teórico de la Ergonomía de la Actividad Aplicada a la Calidad de Vida en el Trabajo - EAA_CVT. Participaron 1.945 trabajadores, lo que corresponde a $63,01 \%$ del personal de la agencia en el momento de la investigación. Se ha utilizado la versión electrónica del Inventario de Evaluación de Calidad de Vida en el Trabajo - IE_CVT como instrumento. Los resultados indican que la calidad de vida en el trabajo, a visión de los participantes de la investigación, se refiere a cuerpo gerencial capacitado, oportunidades iguales de capacitación, ambiente de trabajo saludable, satisfacción con el trabajo, equilibrio entre salud, productividad y vida social, trabajo como origen de realización $y$ placer, y ambiente cooperativo entre compañeros y espacio de charla. Como origen de bienestar en el trabajo, los trabajadores dijeron ser el sentimiento de gustar de las actividades que uno realiza, la posibilidad de ascensión profesional, el hecho de tener tiempo para tratar asuntos personales, la satisfacción de servir a la sociedad con calidad, las relaciones socio-profesionales harmoniosas tanto con compañeros de trabajo cuanto con jefes inmediatos, el sentimiento de tarea cumplida y el espacio existente de libertad de acción, las condiciones de trabajo ideales, sueldo satisfactorio y la flexibilidad de horario. Los principales motivos para el malestar en el trabajo en el contexto de la agencia reguladora fueron la falta de preparo y arrogancia gerencial, injerencia, clientelismo y la ocupación de puestos comisionados por personas sin aprobación en oposiciones, relación de conflicto con usuarios, precariedad de trabajadores externalizados, exceso de burocracia, falta de planeamiento, ejecución de tareas repetitivas y precarias condiciones laborales. Los resultados son discutidos a la luz de la literatura en el campo de las ciencias del trabajo y de la da EAA_CVT.

Palabras clave: calidad de vida en el trabajo; ergonomía de la actividad; bienestar en el trabajo; agencia reguladora brasileña.

\section{Resumé}

Le but de cette recherche a été celui d'identifier les représentations des employés dans une agence régulatrice brésilienne à propos de la qualité de vie au travail et des souces de bien-être et mal-être dans le travail. La recherche a été basée sur le cadre théorique de l'Ergonomie de l'Activité Apliquée à la Qualité de Vie au Travail EAA_QVT. Exactement 1.945 employés ont prticipé à la recherche, ce qui correspond à $63,01 \%$ de tous les travailleurs de l'agence au moment de la recherche. On a utilisé la version electronique de l'Inventaire d'Avaliation de Qualité de Vie au Travail - IA_ QVT-comme instrument. Les résultats indiquent que la qualité de vie au travail au point de vue des participants à la recherche correspond à un cadre d'employés capacité à la gestion, le même niveau d'opportunité de capacitation, ambiance de travail saine, satisfaction de travailler, équilibre entre santé, productivité et vie sociale, travail comme source de complétude et plaisir, e ambience de coopération entre les collègues et l'espace de la parole. Comme source de bien-être au travail, les travailleurs ont listé : le sentiment d'aimer l'activité rélisée, la possibilité d'évolution profissionelle, possibilité aussi d'avoir du temps pour traiter das sujets de la vie personelle, la satisfaction de donner des services de qualité à la société, les relations socio-professionnelles pleines d'harmonie avec les collègues et également avec les chefs imédiats, le sentiment d'accomplissement des obligations et l'espace de liberté, les conditions adéquates de travail, la rémunération satisfaisante et la flexibilité des horaires. Les principaux souces de mal-être au travail dans le contexte de l'agence régulatrice sont: le manque de qualification et l'arrogance des gestionaires, la mauvaise gestion, le clientélisme et l'occupation des postes public de travail par des personnes qui n'avaient pas fait des examens pour cela, intération conflitueuse avec les utilisateurs, la précarité des externalisation sous-traitance, l'excès de bureaucratie, le manque de plans, les execussion des activités de répétition et la précarité de la situation de travail. Les résultats sont discutés d'après la litérature du domaine des sciences du travail et de l'EAA_QVT. 
Mots-clés: qualité de vie au travail; ergonomie de l'áctivité; bien-être au travail; mmal-être au travail; agence régulatrice brésilienne.

Em um momento histórico em que globalização, mudanças organizacionais, novos modelos de gestão, competitividade, produtividade, sustentabilidade, entre outros temas, são constantemente discutidos e focados nas organizações, sejam elas públicas ou privadas, percebe-se que talvez pouca importância seja dada ao elemento central para que essas questões sejam gerenciadas eficazmente: o trabalhador. Recorrentemente, o que se espera é que este esteja constantemente se adequando ao multíplice e turbulento mundo do trabalho.

De fato, o que parece se evidenciar nos contextos organizacionais é que, se de um lado, exige-se muito, de outro, pouco é oferecido a esse trabalhador enquanto peçachave nas organizações. As constantes mudanças no mundo do trabalho, com destaque para o uso intensivo das Novas Tecnologias da Informação e da Comunicação (NTIC), vem exigindo dos trabalhadores a necessidade crescente de adaptação constante, acelerada e adequada, exigindo-lhes resiliência e desenvolvimento de estratégias de mediação operatórias cada vez mais sofisticadas.

$\mathrm{O}$ que se percebe é que o corpo gerencial e seus respectivos modelos de gestão organizacional e do trabalho, de um modo geral, preocupam-se em adequar o funcionário ao contexto apresentado, transformando-o em apenas mais uma "engrenagem" ou a variável de ajuste da estrutura organizacional. Tal situação contraria, globalmente, o sentido do trabalho como uma atividade humana ontológica singular, calcada em estratégias de mediação individual e coletiva por meio das quais os sujeitos buscam garantir os meios necessários à sobrevivência, proporcionar o seu bem-estar físico, psicológico e social e, ainda, responder às tarefas prescritas (Ferreira, 2003).

A reestruturação produtiva, iniciada na década de 1970 com o advento da revolução tecnológica e da crise mundial do petróleo, foi o principal marco da formação dessa nova configuração econômica, social e política, e surgiu como alternativa ao modelo taylor-fordismo, relativamente esgotado, então vigente. $\mathrm{O}$ cenário que se configurou com base nessas inovações causou mudanças nas relações produtivas, com destaque para a intensificação do trabalho, apontada como um dos principais prejuízos para os trabalhadores.

Em grande parte das organizações em países em ascensão (como o Brasil) tal cenário mostra-se híbrido, refletindo uma combinação entre a modernidade das inovações tecnológicas e o conservadorismo do modelo taylor-fordista (Ferreira, 2008). Assim, o que se vê é que a inflexibilidade de um modelo "engessado" de gestão dificulta os ganhos que a tecnologia poderia promover em termos de bem-estar no trabalho.

Inserido no contexto apresentado, e para acompanhar as tendências das grandes economias mundiais, o Brasil passou, a partir da segunda metade da década de 1990, a atuar um contexto de privatização e de redefinição em diversos setores da economia, embalado pelo modismo internacional do neoliberalismo. Nesse cenário surgiram as agências reguladoras federais, acompanhando um movimento que tinha como objetivo a expansão da oferta e melhoria de serviços, de produtos gerados e dos preços praticados nesses mercados (Oliveira Filho, Fujiwara, \& Machado, 2005). A criação das agências reguladoras acompanhou o processo de abertura de alguns mercados e conferiu mais independência técnica ao marco regulatório (Oliveira Filho, 2005).

Estudos sobre as agências reguladoras, como os de Oliveira Filho (2005), Pó e Abrucio (2006) e Pacheco (2006), apresentam de maneira incipiente pesquisas que analisam de forma crítica, com base em resultados empíricos, a pertinência da criação do setor regulatório no Brasil. Essa lacuna decorre, provavelmente, da recente história desses órgãos, com quinze anos de existência em média. Entretanto, é de extrema importância avaliar se o marco regulatório foi positivo para o crescimento dos setores em questão.

Pacheco (2006) afirma que, ainda que não haja argumentos ou evidências na literatura, a criação das agências evidenciou inovação institucional acompanhando a experiência internacional, especialmente no que se refere a sua autonomia e às suas formas de controle. $\mathrm{O}$ estudo realizado por Oliveira Filho (2005) teve como objetivo construir indicadores que permitissem relacionar a competitividade setorial do desenho regulatório brasileiro. Os resultados obtidos não permitiram concluir relação clara entre o nível de independência das agências e o desempenho dos setores regulados. Entretanto, essa é uma visão mecânica, operacional e economicista da atuação das agências. Cabe questionar se os resultados implicam em reflexos positivos nos cenários de trabalho das agências no que se refere, por exemplo, à gestão de pessoas.

Nesse sentido, preconiza-se a necessidade de realização de pesquisas e intervenções nesses campos de trabalho com vistas a caracterizar esses contextos e analisar as vertentes relacionadas à gestão do trabalho, à qualidade de vida no trabalho, à saúde e segurança no trabalho, entre outros aspectos relacionados à perspectiva do trabalhador, sem perder de vista a busca por melhorias de gestão que propiciem melhorias dos serviços à sociedade. Esse é um desafio posto às ciências do trabalho, como um importante campo de intervenção.

No que se refere à qualidade de vida no trabalho, o termo tem sido pauta de discussão cada vez mais intensa 
nas organizações e nos ambientes acadêmicos. Embora a temática venha sendo debatida há aproximadamente quatro décadas, ainda não há consenso entre autores quanto ao seu conceito (Bragard, Dupuis, Razavi, Reynaert, \& Etienne, 2012; Brunalt, Fouquereau, Colombat, Gillet, El-Hage, Camus, \& Gaillard, 2013; Fernandes, 1996; Ferreira, 2011b; Ferreira, 2012; Ferreira, Alves, \& Tostes, 2009; Josiah, Odera, Chepkuto, \& Okaka, 2012; Lacaz, 2000; Lawler, 1982; Nadler, \& Lawler, 1983; Nayeri, Salehi, \& Noghabi, 2011; Sampaio, 2012; Tolfo, Silva, \& Luna, 2009).

Percebe-se que os elementos centrais que compõem a concepção de QVT perpassam por vários pontos, como saúde física e mental, segurança, relações de trabalho, estresse e formas de evita-lo, humanização, entre outros. De maneira geral, um ponto comum dos conceitos é o de um movimento de reação ao rigor dos métodos tayloristas (Sampaio, 2012). Todavia, parece haver um predomínio de quatro eixos que orientam a visão e os estudos dos autores pesquisados:

a) QVT e satisfação com o trabalho: especialmente na década de 1970, QVT passou a ser associada à satisfação dos empregados com o trabalho. A partir dessa época, diversos autores têm relacionado QVT e satisfação (Brunault et al., 2013; Lee et al., 2013; Marta et al., 2013; Martel \& Dupuis, 2006; Sirgy et al., 2001, Sirgy et al., 2008; Tolfo, Silva, \& Luna, 2009; Zhao et al., 2012).

b) QVT e produtividade: o precursor dessa linha foi F. Herzberg (Josiah et al., 2012) e há diversos estudos que evidenciam forte relação entre QVT e performance/produtividade (Abarqhouei \& Nasab, 2011; Aketch et al., 2012; An, Hee, \& Ruggiero, 2010; Josiah et al., 2012; Lawler, 1982; Nayeri, Salehi, \& Noghabi, 2011).

c) QVT e bem-estar: Nos últimos anos, estudos têm associado a QVT ao bem-estar dos empregados. Esta é uma perspectiva que dissocia o olhar exclusivo para questões organizacionais e/ou econômicas (Ferreira, 2011a, 2012; Li \& Yeo, 2011; Sampaio, 2012).

d) QVT e comprometimento: pesquisas vêm evidenciando correlação positiva entre comprometimento organizacional, especialmente na dimensão afetiva, e QVT (Huang et al., 2007; Koonmee, Singhapakdi, Virakul, \& Lee, 2010; Zhao et al., 2012).

Analisando os conceitos de QVT propostos pelos autores, verifica-se a ausência de elementos considerados centrais para a percepção de QVT, que muitas vezes estão relacionados a variáveis organizacionais, especialmente da organização do trabalho, como autonomia, controle e significado do trabalho. Entende-se, portanto, que a QVT deve ser avaliada com base no olhar do trabalhador sobre as variáveis organizacionais.

Alinhado a esse entendimento, neste estudo, adotouse como referencial teórico-metodológico a abordagem da Ergonomia da Atividade Aplicada à Qualidade de Vida no Trabalho (EAA_QVT) (Ferreira, 2011a, 2011b, 2012). Conforme a abordagem, o conceito de QVT engloba duas perspectivas independentes:

- Sob a ótica das organizações: QVT é representada pelas normas, diretrizes e práticas que visam à promoção do bem-estar individual e coletivo, o desenvolvimento pessoal dos trabalhadores e o exercício da cidadania organizacional.

- Sob a ótica dos trabalhadores: QVT são as representações que os trabalhadores têm sobre a organização em que estão inseridos, indicando predomínio de vivências de bem-estar no trabalho, de reconhecimento institucional e coletivo, de possibilidades de crescimento profissional e de respeito à individualidade.

A abordagem promotora, com viés preventivo, e proposta por Ferreira (2008, 2011b, 2011c, 2012) vem como alternativa no sentido de identificar os fatores geradores do mal-estar no trabalho, de promover o resgate do sentido humano do trabalho, enxergando a eficiência e a eficácia organizacional como resultantes da percepção de bem-estar e do sentimento de felicidade no trabalho. A perspectiva da abordagem promotora é de contribuir para se alcançar quatro dimensões interdependentes: vigilância em saúde e segurança; assistência psicossocial; promoção de bem-estar no trabalho; e felicidade no trabalho.

O principal pressuposto metodológico que norteia a abordagem promotora, fundamentado teoricamente na Ergonomia da Atividade, é perguntar a quem trabalha o que é qualidade de vida no trabalho. O uso da pergunta deve ser ponto de partida para uma atuação mais efetiva em QVT. Além disso, identificar as possíveis fontes de bemestar e mal-estar no trabalho se faz necessário uma vez que representações positivas indicam bem-estar no trabalho e, consequentemente, existência de QVT. Por outro lado, representações negativas indicam presença de mal-estar no trabalho levando a risco de adoecimento.

\section{Bem-estar e Mal-estar no Trabalho}

As dimensões bem-estar e mal-estar no trabalho têm sido discutidas e avaliadas enquanto um dos elementos para se compreender a percepção do indivíduo sobre o contexto de trabalho. Entretanto, verifica-se que não há consenso na literatura sobre seus conceitos e que na maior parte das 
publicações, não há a definição do constructo, especialmente no que se refere ao mal-estar no trabalho.

O conceito de bem-estar no trabalho pode ser compreendido com base em três componentes associados a vínculos positivos com o trabalho: satisfação no trabalho, envolvimento com o trabalho e comprometimento organizacional afetivo (Siqueira \& Padovam, 2008). Essa concepção foi elaborada tendo por base o constructo bemestar subjetivo, que envolve um modelo hierárquico de felicidade.

Aproximar os termos bem-estar e felicidade é também a perspectiva de Paschoal, Torres e Porto (2010). Nesse sentido, bem-estar no trabalho é entendido como a prevalência de emoções positivas no trabalho e a percepção do indivíduo de que sua atuação permite o desenvolvimento de seus potenciais e alcance de suas metas de vida. Dessa forma, o bem-estar no trabalho inclui aspectos afetivos e cognitivos e é organizado em torno de três fatores: afeto positivo, afeto negativo e realização pessoal no trabalho.

No que se refere ao mal-estar no trabalho, a maior parte dos estudos relaciona este construto com os fatores que o promovem, como condições precárias de trabalho, organização do trabalho inadequada e esgotamento profissional (Araújo, Sena, Viana, \& Araújo, 2005; Chávez, 2009; Maciel, Sena, \& Saboia, 2006). Há ainda outras pesquisas que apontam o mal-estar relacionado a variáveis individuais, como vivências subjetivas na infância (Silva, 2005) e estresse (Aznar, Rodríguez, \& Aznar, 2006).

Bendassoli (2011, p. 67) analisa a relação do homem com o trabalho ao longo da história e afirma que "o malestar na civilização é, na verdade, um mal-estar do trabalho", argumentando que o desenvolvimento da psicopatologia do trabalho é o "sintoma maior" dessa constatação. O autor relaciona o sofrimento no trabalho como uma modalidade de mal-estar, discutindo o papel da clínica do trabalho como alternativa de intervenção.

Em uma perspectiva de trazer à luz uma definição mais clara sobre mal-estar no trabalho, Ferreira e Seidl (2009) apontam que o conceito pode ser compreendido como uma espécie de "reverso da medalha": compreende-se melhor o mal-estar no trabalho pela ausência dos elementos estruturantes do bem-estar no trabalho. Neste sentido, para compreender-se o mal-estar no trabalho, deve-se resgatar o conceito de bem-estar no trabalho e o que tal conceito inclui. Tal resgate deve se circunscrever no Contexto de Produção de Bens e Serviços (CPBS), composto por três dimensões articuladas: Condições de Trabalho, Organização do Trabalho e Relações Socioprofissionais.

Os conceitos de bem-estar e mal-estar no trabalho adotados nesta pesquisa vão ao encontro do que foi proposto por Ferreira e Seidl (2009). Conforme a EAA_QVT, bemestar no trabalho diz respeito a um sentimento agradável que tem origem nas situações de trabalho e se manifesta de forma individual ou coletiva. O mal-estar no trabalho, por sua vez, refere-se a sentimentos desagradáveis que se originam a partir das situações de trabalho se manifestando individual ou coletivamente (Ferreira, 2012). Esse estado psicológico se configura como uma representação mental dos trabalhadores, sendo fruto da avaliação que estes fazem dos fatores que estruturam a QVT: condições, organização e relações socioprofissionais de trabalho, reconhecimento e crescimento profissional e elo trabalho-vida social, conforme apresenta a Tabela 1.

$\mathrm{O}$ bem-estar e o mal-estar em contextos organizacionais podem ser investigados empiricamente por meio das múltiplas formas de manifestação dos indivíduos e/ou do coletivo, de maneira que a verbalização e a escrita são os principais modos de expressão. O desafio posto aos estudos que buscam analisar esses construtos pode ser delineado sob dois aspectos: em primeiro lugar, é fundamental o aprofundamento teórico na temática. É preciso, além de estabelecer definições mais abrangentes, investigar como as representações de bem-estar mal-estar são formadas; em segundo lugar, a realização de pesquisas com maior consistência teórico-metodológica poderá propiciar a pesquisadores e gestores o desenvolvimento de formas de atuar, de maneira mais concreta, na redução das fontes de mal-estar no trabalho e, por outro lado, no fortalecimento das fontes de bem-estar.

Com base no exposto, o objetivo desta pesquisa consistiu em identificar as representações de trabalhadores de uma agência reguladora brasileira acerca da qualidade de vida no trabalho e das fontes de bem-estar e mal-estar no trabalho. As questões que nortearam o desenvolvimento da pesquisa foram:

- Na opinião dos trabalhadores da agência, o que é qualidade de vida no trabalho?;

- Quais são as principais fontes de bem-estar no trabalho em uma agência reguladora?; e

- Quais são as principais fontes de mal-estar no trabalho em uma agência reguladora?

Com base nesse delineamento, o artigo identifica, a partir do olhar de quem trabalha, quais as variáveis que compõem a qualidade de vida no trabalho e as principais fontes de bem-estar e mal-estar no trabalho no grupo pesquisado. 
Tabela 1

Descrição dos fatores estruturantes de QVT

Fator 1: Condições de Trabalho $(\alpha=0,90)$

Fator 2: Organização do Trabalho $(\alpha=0,73)$

Fator 3: Relações Socioprofissionais $(\alpha=0,89)$

Fator 4: Reconhecimento e Crescimento Profissional $(\alpha=0,91)$

Fator 5: Elo Trabalho-Vida Social $(\alpha=0,80)$
Expressa as condições físicas (local, espaço, iluminação, temperatura), materiais (insumos), instrumentais (equipamentos, mobiliário, posto), suporte (apoio técnico) que influenciam a atividade de trabalho e colocam em risco a segurança física. Esse fator é constituído de 12 itens. Exemplo: "O local de trabalho é confortável".

Expressa as variáveis de tempo (prazo, pausa), controle (fiscalização, pressão, cobrança), traços das tarefas (ritmo, repetição), sobrecarga e prescrição (normas) que influenciam a atividade de trabalho. Esse fator é constituído de 9 itens. Exemplo: "No [nome do órgão], as tarefas são repetitivas".

Interações socioprofissionais em termos de relações com os pares (ajuda, harmonia, confiança), com as chefias (liberdade, diálogo, acesso, interesse, cooperação, atribuição e conclusão de tarefas), comunicação (liberdade de expressão) ambiente harmonioso e conflitos que influenciam a atividade de trabalho. Esse fator é constituído de 16 itens. Exemplo: "É comum o conflito no ambiente de trabalho".

Expressa variáveis relativas ao reconhecimento no trabalho (existencial, institucional, realização profissional, dedicação, resultado alcançado) e ao crescimento profissional (oportunidade, incentivos, eqüidade, criatividade, desenvolvimento), que influenciam a atividade de trabalho. Esse fator é constituído de 14 itens. Exemplo: "Sinto-me reconhecido pela instituição onde trabalho".

Expressa as percepções sobre a instituição, o trabalho (prazer, bem-estar, zelo, tempo passado no trabalho, sentimento de utilidade, reconhecimento social) e as analogias com a vida social (casa, família, amigos) que influenciam a atividade de trabalho. Esse fator é constituído de 10 itens. Exemplo: "A sociedade reconhece a importância do meu trabalho".

\section{Método}

\section{Caracterização do Campo}

A Agência é uma entidade da Administração Indireta denominada Autarquia Especial, não sendo subordinada hierarquicamente a nenhum órgão de governo, cujas decisões só podem ser contestadas judicialmente. Tem como missão promover o desenvolvimento de um setor estratégico do país de modo a dotá-lo de uma moderna e eficiente infraestrutura, capaz de oferecer à sociedade serviços adequados, diversificados e a preços justos, em todo o território nacional.

À época da coleta de dados, a agência tinha em seu corpo funcional um total de 3.087 trabalhadores. Destes, 1.555 são servidores estatutários, que podem ser efetivos, específicos ou requisitados de outros órgãos, enquanto 1.532 são terceirizados ou estagiários.

A agência possui 11 escritórios regionais (ER) em todos os estados brasileiros, além de 08 unidades operacionais (UO) nos estados de Espírito Santo, Santa Catarina, Alagoas, Paraíba, Mato Grosso, Mato Grosso do Sul, Tocantins, Sergipe, Rio Grande do Norte, Piauí, Maranhão, Amapá, Rondônia, Acre e Roraima. Do universo de trabalhadores, 1.722 estão sediados em Brasília, enquanto 1.365 estão lotados em ERs e UOs.

\section{Participantes}

Participaram da pesquisa 1.945 pessoas, o que corresponde a 63,01\% do coletivo de trabalhadores da agência, sendo que a participação de servidores efetivos $(57 \% ; N=1.108)$ foi razoavelmente superior à participação dos terceirizados/estagiários $(43 \% ; \mathrm{N}=837)$. A amostra é não probabilística, por conveniência e de resposta voluntária, ou seja, os trabalhadores escolhiam participar ou não.

Quanto ao perfil demográfico dos participantes, houve o predomínio de trabalhadores do sexo masculino $(61 \% ; \mathrm{N}=1.186)$, com faixa etária entre 30 e 39 anos (32 $\% ; \mathrm{N}=621)$ e com escolaridade de nível superior $(33,68 \%$; $\mathrm{N}=655$ ).

No que diz respeito às características profissiográficas dos participantes do diagnóstico, levando em consideração o banco de dados dos trabalhadores da agência, foram levantadas informações diferenciadas entre os dois grupos. No grupo dos servidores, houve predominância de ocupantes do cargo de técnico administrativo $(47 \% ; \mathrm{N}=521)$, ocupantes de cargo não comissionado $(74 \% ; \mathrm{N}=820)$ e trabalhadores do quadro efetivo da casa $(80 \% ; \mathrm{N}=886)$. No grupo dos terceirizados/estagiários, participaram em maior 
número os terceirizados e prestadores de serviço que atuam na região Centro-Oeste (59\%; $\mathrm{N}=494)$ e ocupantes do cargo de atendente $(25,50 \% ; \mathrm{N}=214)$. O tempo médio de trabalho na agência foi de 4,5 anos $(\mathrm{DP}=5,10)$.

\section{Instrumento}

Utilizou-se como instrumento o Inventário de Avaliação de Qualidade de Vida no Trabalho (IA_QVT) (Ferreira, 2009), disponibilizado via internet, em site externo ao órgão. O IA_QVT é composto por uma parte quantitativa e uma qualitativa, além de questões sobre perfil profissiográfico e demográfico. A parte quantitativa é composta por 61 itens associados a uma escala do tipo likert de concordância de 11 pontos, que mensuram cinco fatores estruturantes de Qualidade de Vida no Trabalho. A parte qualitativa é composta por quatro questões abertas: "Na minha opinião, Qualidade de Vida no Trabalho é..."; "Quando penso no meu trabalho no órgão, o que me causa mais bem-estar é..."; "Quando penso no meu trabalho no órgão, o que me causa mais mal-estar é..." e "Comentários e Sugestões". Neste estudo, serão apresentados os resultados referentes à parte qualitativa do inventário.

\section{Procedimentos}

Para proceder à coleta de dados, foi realizada a sensibilização dos trabalhadores por meio de palestras proferidas aos gestores e demais trabalhadores, além da utilização das seguintes mídias: folder-convite, flyers, cartazes, carta do presidente aos trabalhadores, e-mails e chamadas na intranet da agência, com atuação supervisionada da área de Comunicação Social do órgão.

Visando garantir o sigilo dos trabalhadores e a confidencialidade dos dados, foram gerados 4.000 códigos de acesso, distribuídos de forma aleatória. O participante, ao entrar na página do inventário, inseria o código. Nesta tela, o participante era informado de que a desistência em responder a qualquer momento não the acarretaria qualquer prejuízo ou danos e que os resultados seriam tratados de forma agrupada para fins do diagnóstico.

A versão eletrônica do inventário ficou hospedada em um site externo à organização, disponível durante o período de 19 dias.

\section{Análise dos Dados}

Os resultados foram tratados por meio do software Alceste - Análise Lexical de Contexto de um Conjunto de Segmentos de Textos (Reinert, 1990), versão 4,7. O Alceste identifica informações essenciais das respostas a fim de extrair os Núcleos Temáticos Estruturadores do Discurso (NTED), oferecendo testes estatísticos para analisar os dados textuais extraídos no texto.
O software segmenta o texto analisado em grandes unidades, denominadas Unidades de Contexto Iniciais (UCI). O conjunto de UCIs determina o corpus de análise, que deve constituir-se num conjunto textual centrado em um tema (Camargo, 2005). Ressalta-se que o Alceste analisa um corpus com tamanho mínimo de 10.000 caracteres.

Após o reconhecimento das indicações das UCIs, o software divide o material em Unidades de Contexto Elementares (UCE), formando os Núcleos Temáticos Estruturadores do Discurso e descrevendo-os. A UCE constitui-se de segmentos de textos (enunciados linguísticos) definidos com proposições e frases nos quais o pensamento é anunciado (Fonseca, 2010).

A análise estatística efetuada consiste em duas etapas: na primeira, o software gera uma Classificação Hierárquica Descendente (CHD) que calcula as partições em classes lexicais e apresenta suas oposições sob a forma de dendograma. No segundo momento, efetua-se uma Análise Fatorial de Correspondência (AFC) a qual permite visualizar, sob a forma de um plano fatorial, as oposições resultantes da CHD (Ribeiro, 2009).

Os resultados são apresentados sob a forma de dendogramas que demonstram as relações existentes entre as classes e que possibilitam a visualização das relações entre palavras, dentro de cada classe. Além disso, são identificados extratos das listas de UCEs selecionadas por núcleo temático, contendo frases típicas dos discursos que são representativas de cada núcleo.

\section{Resultados e Discussão}

A parte qualitativa do IA_QVT permite identificar a concepção que os trabalhadores têm de qualidade de vida no trabalho, bem como as principais fontes de bem-estar e de mal-estar no trabalho no contexto organizacional.

A análise da questão "Na minha opinião, qualidade de vida no trabalho é..." gerou seis núcleos temáticos. $\mathrm{Na}$ leitura das verbalizações, verificou-se que os núcleos tratavam de cooperação entre colegas, da importância de ter espaço de fala, de ter condições de trabalho adequadas, de possibilidades de desenvolvimento gerencial e de capacitação, da satisfação e do prazer com o trabalho em um ambiente saudável e do equilíbrio entre saúde, produtividade e vida social. Os percentuais de cada núcleo e exemplos dos segmentos representativos dos discursos são apresentados na Tabela 2.

$\mathrm{O}$ resultado apresentado indica uma visão abrangente e rica dos trabalhadores da agência quanto à percepção de QVT. Verifica-se que, para eles, QVT não se refere às práticas de natureza assistencial e paliativa, típicas de vários programas de qualidade de vida no trabalho. Ao contrário, as representações dos trabalhadores dizem respeito a aspectos das condições, organização e relações socioprofissionais 
Tabela 2

Núcleos temáticos, percentuais e exemplos de segmentos representativos do conceito de qualidade de vida no trabalho

\begin{tabular}{|c|c|c|}
\hline Núcleos Temáticos & Percentuais & Segmentos representativos \\
\hline \multirow{3}{*}{$\begin{array}{l}\text { Desenvolvimento gerencial e } \\
\text { oportunidades iguais de capacitação }\end{array}$} & \multirow{3}{*}{$28,55 \%$} & Oportunidades de capacitação iguais para todos, pois é o que não acontece; \\
\hline & & $\begin{array}{l}\text { Trabalhar sob o comando de gerentes devidamente preparados e com } \\
\text { comportamentos uniformes em todos os setores da agência; }\end{array}$ \\
\hline & & $\begin{array}{l}\text { Uma boa gestão de pessoal por parte da gerência, fica aqui uma sugestão de } \\
\text { treinamento de RH, gestão, administração para todos os gerentes da agência. }\end{array}$ \\
\hline \multirow{3}{*}{$\begin{array}{l}\text { Ambiente saudável e satisfação com } \\
\text { o trabalho }\end{array}$} & \multirow{3}{*}{$21,43 \%$} & Ter ambiente saudável para realizar as atividades laborais; \\
\hline & & $\begin{array}{l}\text { É desempenhar atividades laborais com entusiasmo e satisfação, alcançando } \\
\text { resultados que tenham sentido e utilidade para si e para a sociedade; }\end{array}$ \\
\hline & & $\begin{array}{l}\text { Sentir-se plenamente satisfeito em executar suas atividades, em um ambiente } \\
\text { saudável e propicio para a produtividade. }\end{array}$ \\
\hline \multirow{2}{*}{$\begin{array}{l}\text { Equilíbrio entre saúde, produtividade } \\
\text { e vida social }\end{array}$} & \multirow{2}{*}{$17,47 \%$} & $\begin{array}{l}\text { Qualidade de vida no trabalho deve propiciar e estimular hábitos saudáveis do } \\
\text { servidor, a fim de que este bem-estar entre os servidores e os servidores e sua } \\
\text { família promovam reflexos positivos na produtividade no trabalho; }\end{array}$ \\
\hline & & $\begin{array}{l}\text { Qualidade de vida é mais do que ter uma boa saúde física ou mental. É estar de } \\
\text { bem com você mesmo, com a vida, com as pessoas queridas, balanço entre vida } \\
\text { pessoal e profissional, tempo de lazer, enfim, estar em equilíbrio. }\end{array}$ \\
\hline \multirow{3}{*}{ Trabalho como fonte de prazer } & \multirow{3}{*}{$14,52 \%$} & $\begin{array}{l}\text { Chegar para o dia de trabalho animado e motivado, e sentir que aquilo que você } \\
\text { faz lhe dá prazer e é útil para a sociedade; }\end{array}$ \\
\hline & & É sempre gostar de voltar no outro dia para trabalhar; \\
\hline & & $\begin{array}{l}\text { Ter prazer em ir trabalhar, ter prazer no que faz e não voltar para casa abatido, } \\
\text { triste, estressado ou desanimado com os acontecimentos ocorridos durante o } \\
\text { periodo de trabalho. }\end{array}$ \\
\hline \multirow{3}{*}{$\begin{array}{l}\text { Cooperação entre colegas e espaço } \\
\text { de fala }\end{array}$} & \multirow{3}{*}{$10,57 \%$} & $\begin{array}{l}\text { Sentir-se confortável em manifestar opiniões e ideias além da harmonia no } \\
\text { espaço de trabalho entre outros; }\end{array}$ \\
\hline & & Cooperação e coleguismo entre a equipe de trabalho; \\
\hline & & $\begin{array}{l}\text { Ter um bom ambiente de trabalho e pessoas dispostas a ajudar, refletindo a união } \\
\text { do grupo. }\end{array}$ \\
\hline \multirow{2}{*}{ Condições de trabalho adequadas } & \multirow{2}{*}{$7,46 \%$} & $\begin{array}{l}\text { É ter um ambiente que lhe dê condições de trabalho adequadas, como cadeiras } \\
\text { boas, computadores bons, iluminação boa, headset em bom estado, ambiente } \\
\text { com boa higiene, ar condicionado com limpeza adequada; }\end{array}$ \\
\hline & & $\begin{array}{l}\text { Equipamentos e ambientes adequados e ergonômicos, iluminação e temperatura } \\
\text { adequados, disponibilidade de material de uso no trabalho, prédio e instalações } \\
\text { adequadas e bem apresentáveis. }\end{array}$ \\
\hline
\end{tabular}

de trabalho, reconhecimento e crescimento profissional e elo trabalho-vida social, conforme preconiza a EAAQVT (Ferreira, 2011c; Ferreira, Ferreira, Antloga, \& Bergamaschi, 2009; Ferreira, Alves, \& Tostes; Ferreira \& Seidl, 2009).

As respostas dos trabalhadores da agência convergem com resultados obtidos em outras pesquisas que utilizaram a abordagem da EAAQVT (Andrade, 2011; Branquinho, 2010; Feitosa, 2010; Fernandes, 2013; Figueira 2014). Nesses estudos, os trabalhadores associam QVT aos sentimentos de prazer e satisfação com o trabalho, à prática de reconhecimento, respeito e valorização profissional, a condições de trabalho adequadas, a relações harmoniosas e à organização humanizada do trabalho.

Na questão "Quando penso no meu trabalho na agência, o que me causa mais bem-estar é...", a análise do Alceste possibilitou a identificação de cinco núcleos temáticos: gostar do que faz, crescimento profissional e tempo para a vida pessoal; prestação de serviços de qualidade à sociedade; relações socioprofissionais harmoniosas com colegas e chefia imediata; sentimento de dever cumprido e liberdade de ação; e condições de trabalho adequadas, remuneração satisfatória e flexibilidade de horário, conforme descrito na 
Tabela 3.

Nota-se que as fontes de bem-estar no trabalho relatadas pelos trabalhadores da agência foram, também, destacadas no conceito de qualidade de vida no trabalho. Esse dado evidencia o que aponta o modelo teórico da EAAQVT: as representações positivas indicam vivências de bem-estar no trabalho e, consequentemente, a existência qualidade de vida no trabalho (Ferreira, 2012).

Os núcleos temáticos "gostar do que faz, crescimento profissional e tempo para a vida pessoal" e "sentimento de dever cumprido e liberdade de ação" destacam aspectos importantes no contexto da agência. Esses núcleos mostram a afinidade do grupo em questão com o trabalho que realiza. Essa é uma questão que foi identificada como fator que compõe o conceito de QVT para uma parcela do grupo de trabalhadores (núcleo temático "trabalho como fonte de prazer", $14,52 \%$ do discurso) e condiz com a literatura que aponta a necessidade do resgate do sentido do trabalho, demonstrando a centralidade do trabalho na vida do homem (Ferreira \& Mendes, 2003; Ferreira, Alves, \& Tostes, 2009), e da perspectiva de bem-estar no trabalho como fonte de felicidade (Paschoal \& Tamayo, 2008; Paschoal et al., 2010).

Conforme $26,20 \%$ do discurso, os participantes da

Tabela 3

Núcleos temáticos, percentuais e exemplos de segmentos representativos das fontes de bem-estar no trabalho

\begin{tabular}{|c|c|c|}
\hline Núcleos Temáticos & Percentuais & Segmentos representativos \\
\hline \multirow{3}{*}{$\begin{array}{l}\text { Gostar do que faz, crescimento } \\
\text { profissional e tempo para a vida pessoal }\end{array}$} & \multirow{3}{*}{$35,01 \%$} & Saber que tenho meu trabalho e gosto do faço; \\
\hline & & $\begin{array}{l}\text { Saber que vou fazer aquilo que gosto e que mesmo me empenhando ao } \\
\text { máximo durante a jornada, terei um tempo maior para o lazer ou descanso; }\end{array}$ \\
\hline & & Em saber que posso crescer profissionalmente. \\
\hline \multirow{2}{*}{$\begin{array}{l}\text { Prestação de serviços de qualidade à } \\
\text { sociedade }\end{array}$} & \multirow{2}{*}{$26,20 \%$} & $\begin{array}{l}\text { Que estou a serviço da sociedade, fiscalizando os serviços de telecomunicações } \\
\text { para que sejam prestados adequadamente e com qualidade; }\end{array}$ \\
\hline & & $\begin{array}{l}\text { Poder contribuir, efetivamente, para atender aos anseios da sociedade } \\
\text { depositados nos servidores públicos. }\end{array}$ \\
\hline \multirow{2}{*}{$\begin{array}{l}\text { Relações } \\
\text { harmoniosas } \\
\text { imediata }\end{array}$} & \multirow[b]{2}{*}{$17,38 \%$} & Bom relacionamento com os colegas e a chefia imediata; \\
\hline & & $\begin{array}{l}\text { Boa convivência com meus colegas de trabalho e com minha chefia imediata; } \\
\text { O convívio harmonioso com os colegas de trabalho. }\end{array}$ \\
\hline \multirow{2}{*}{$\begin{array}{l}\text { Sentimento de dever cumprido e } \\
\text { liberdade de ação }\end{array}$} & \multirow{2}{*}{$11,59 \%$} & $\begin{array}{l}\text { Satisfação de dever cumprido, que ao realizar as minhas tarefas, ter a certeza } \\
\text { de que foi bem feito; }\end{array}$ \\
\hline & & $\begin{array}{l}\text { A possibilidade de executar as tarefas com grau de liberdade que não } \\
\text { prejudicam o cumprimento dos prazos. }\end{array}$ \\
\hline \multirow{3}{*}{$\begin{array}{l}\text { Condições de trabalho adequadas, } \\
\text { remuneração satisfatória e flexibilidade } \\
\text { de horário }\end{array}$} & \multirow{3}{*}{$9,82 \%$} & Infraestrutura excelente, ambiente de trabalho agradável e boa remuneração; \\
\hline & & $\begin{array}{l}\text { Saber que trabalho num ambiente confortável e com instalações modernas } \\
\text { e satisfatórias; }\end{array}$ \\
\hline & & A boa remuneração aliada com a flexibilidade de horário. \\
\hline
\end{tabular}

pesquisa percebem a prestação de serviços de qualidade à sociedade como fonte de bem-estar no trabalho. Este é um indicador de que, na perspectiva dos trabalhadores, as agências têm cumprido seu papel social. Essa percepção contribui para a sensação de prazer e satisfação com o trabalho, identificados tanto no conceito de QVT quanto nas fontes de bem-estar no trabalho. Resta, todavia, confrontar este olhar dos respondentes predominantemente positivo sobre o papel da agência com a efetiva prestação de serviços para a sociedade brasileira com base em estudos porventura existentes.

Verifica-se no núcleo "relações socioprofissionais harmoniosas com colegas e chefia imediata" a importância das relações para a percepção de bem-estar no trabalho.
De acordo com Ferreira (2008, 2012), o relacionamento socioprofissional saudável está associado à satisfação com o trabalho e a desempenhos melhores. Além disso, as relações interpessoais dentro do contexto laboral desempenham um papel compensador, especialmente quando as condições e a organização do trabalho são avaliadas negativamente.

Foram identificados quatro núcleos temáticos estruturadores do discurso após a análise da questão "Quando penso no meu trabalho na agência, o que me causa mais mal-estar é...": despreparo e arrogância gerencial, ingerência, clientelismo e cargos de confiança para não concursados; interação conflituosa com os usuários e precariedade dos trabalhadores terceirizados; excesso de burocracia, falta de planejamento e tarefas repetitivas; 
e condições de trabalho precárias. A Tabela 4 apresenta os percentuais de cada núcleo e exemplos dos segmentos representativos dos discursos.

O núcleo temático "despreparo e arrogância gerencial, ingerência, clientelismo, e cargos de confiança para não concursados" demonstra uma realidade que parece se repetir no âmbito do serviço público. Frequentemente vê-se na imprensa escândalos envolvendo as questões levantadas pelos trabalhadores da agência, especialmente quanto ao clientelismo e à ingerência. Ademais, algumas pesquisas realizadas em outros órgãos do serviço público destacam esses aspectos como sendo fonte de sofrimento, mal-estar,

Tabela 4

Núcleos temáticos, percentuais e exemplos de segmentos representativos das fontes de mal-estar no trabalho

\section{Núcleos Temáticos}

Despreparo e arrogância gerencial, ingerência, clientelismo e cargos de confiança para não concursados

Interação conflituosa com os usuários e precariedade dos trabalhadores terceirizados

Excesso de burocracia, falta de planejamento e tarefas repetitivas

$17,12 \%$

$29,33 \%$

(2)

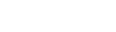

Condições de trabalho precárias

$15,71 \%$

\section{Segmentos representativos}

Excesso de ingerência do governo: deveria haver uma política institucional determinando que cargos até o nível de superintendência, inclusive, deveriam ser ocupados somente por servidores efetivos;

Que sempre temos a sensação de que não estamos servindo a sociedade e sim a interesses particulares de alguns, que a chefia da [nome da agência] está repleta de arrogantes que acham que os servidores são seus empregados pessoais;

A falta de reconhecimento dos servidores concursados, pois os cargos de confiança, cargo comissionado, cargos de alta gerência e de assessoria são, em sua maioria, ocupados por servidores de outros órgãos.

Saber que não posso interagir com o usuário como gente. É muita formalidade
para resolver um problemão. Usuário quando entra em contato conosco não estão buscando maquinas e sim humanos para ajudá-los;

Saber que todo dia eu vou ser ofendida pelo menos por um usuário insatisfeito com as atitudes da [nome da agência] para conclusões que passam anos sem resposta;

Ver as empresas terceirizadas descumprirem o contrato e atrasar o salário, VT, VA dos funcionários que trabalham aflitos por estarem com fome, pagando juros e sem dinheiro pra pagar nem a passagem e a [nome da agência] dizer que não é problema deles.

Realizar tarefas repetitivas e excessivamente burocráticas;

O processo muito amarrado, burocrático e lento;

A repetitividade das atividades, a ausência de procedimentos claros para a execução de algumas ações.

O ambiente de trabalho não é confortável, pois a limpeza é precária onde o carpete está mais velho que tudo, os banheiros são poucos para a utilização de tantas pessoas, o ar condicionado funciona mal, a poeira é muito forte dentro do ambiente;

A deficiência do local de trabalho, sala e móveis precários, pouco espaço físico e das ferramentas de trabalho. descrênça e até desgosto (Maia, 2014; Tavares, 2003).

A questão envolve fatores de ordem política e, muitas vezes, externos à organização, mas também envolve fatores relacionados à organização do trabalho (postura do gestor, descrição e divisão de tarefas, capacitações), às práticas de reconhecimento e às oportunidades de crescimento (Ferreira, 2012). No que cabe à organização, entende-se que uma política de QVT pautada em ações voltadas à formação e desenvolvimento gerencial e à criação de processo seletivo interno para ocupação de cargos comissionados, como já vêm acontecendo em alguns órgãos públicos, certamente irão minimizar os fatores causadores de malestar no trabalho.

A interação conflituosa com os usuários é um problema clássico em organizações públicas e privadas que utilizam o teleatendimento como canal de comunicação. Nesse sentido, a organização do trabalho, centrada em regras rígidas, cobranças excessivas e punições são aspectos 
que contribuem para as queixas dos trabalhadores e são potencializadoras das representações de mal-estar no trabalho (Veras \& Ferreira, 2006).

Observa-se que os participantes da pesquisa relaram condições precárias de trabalho como fonte de mal-estar no trabalho e condições de trabalhos adequadas como fonte de bem-estar no trabalho, assim como ocorreu em outros estudos (Andrade, 2011; Fernandes, 2013). Condições de trabalho precárias podem gerar cansaço, desestímulo e, até mesmo, adoecimento, potencializando as vivências de mal-estar no trabalho (Antloga, 2009; Ferreira \& Mendes, 2003). Por outro lado, condições de trabalho adequadas às necessidades do trabalhador e às características da tarefa contribuem para sentimentos de satisfação e valorização e prevenção de doenças laborais (Abrahão et al., 2009).

Comparando as fontes de bem-estar e mal-estar no trabalho identificados nesta pesquisa com outros estudos que utilizaram a abordagem da EAAQVT (Andrade, 2011; Branquinho, 2010; Feitosa, 2010; Fernandes, 2013; Figueira, 2014), verifica-se a importância das relações socioprofissionais, de um ambiente agradável, das condições de trabalho adequadas e das oportunidades reais de crescimento para a percepção de bem-estar no trabalho. Já fatores relacionados à falta de liberdade, autonomia, reconhecimento e condições precárias de trabalho estão associados a vivências de mal-estar no trabalho.

Ao analisar os resultados encontrados, é possível conjecturar que é primordial para as organizações pensar e agir em QVT de natureza preventiva, construída com base na ótica de quem faz a organização funcionar, ou seja, os trabalhadores. Para isso, é necessário mudar a lógica que estrutura os modelos de gestão do trabalho. Como reforça Ferreira (2006), "novas práticas em qualidade de vida no trabalho necessitam que os protagonistas organizacionais removam valores, crenças e concepções" (p.2).

\section{Considerações Finais}

A análise dos resultados da pesquisa possibilitou identificar que a qualidade de vida no trabalho, no contexto da agência, deve abranger: corpo gerencial capacitado; oportunidades iguais de capacitação; ambiente de trabalho saudável; satisfação com o trabalho; equilíbrio entre saúde, produtividade e vida social; trabalho como fonte de realização e prazer; e ambiente cooperativo entre colegas e espaço de fala.

Como fontes de bem-estar no trabalho da agência, os trabalhadores relacionaram: o sentimento de gostar das atividades que se realiza; a possibilidade de crescimento profissional; a prerrogativa de terem tempo para tratar de assuntos relacionados à vida pessoal; a satisfação de prestar serviços de qualidade à sociedade; as relações socioprofissionais harmoniosas tanto com os colegas como com as chefias imediatas; o sentimento de dever cumprido e o espaço existente de liberdade de ação; as condições de trabalho adequadas; a remuneração satisfatória; e a flexibilidade de horário.

As principais fontes de mal-estar no trabalho no contexto da agência reguladora pesquisada relacionaramse ao despreparo e arrogância gerencial, ingerência, clientelismo e a ocupação de cargos comissionados por pessoas não concursadas, à interação conflituosa com usuários, à precariedade dos trabalhadores terceirizados, ao excesso de burocracia, à falta de planejamento, à execução de tarefas repetitivas e às condições de trabalho precárias.

Os trabalhadores destacaram ainda a necessidade de meritocracia na distribuição de cargos, ressaltando o tratamento desigual entre sede e unidades descentralizadas, a necessidade de definição de competências, de melhoria nos contratos de prestação de serviços e de igualdade de tratamento entre servidores efetivos e terceirizados.

A pesquisa pode ser considerada uma ação de promoção de qualidade de vida no trabalho, uma vez que propiciou um espaço de livre expressão sobre o contexto de trabalho dos participantes. Além disso, a estratégia de envolver os trabalhadores no diagnóstico e, futuramente, na elaboração da política e do programa de QVT, possibilita que esses se insiram de forma participativa nas atividades, como agentes do processo de transformação, podendo, assim, contribuir para a construção da cultura de QVT do órgão.

A Ergonomia da Atividade Aplicada a Qualidade de Vida no Trabalho possibilitou compreender a relação entre as representações dos trabalhadores e as dimensões analíticas da abordagem: qualidade de vida no trabalho, bem-estar e mal-estar no trabalho. Evidenciou, ainda, que qualidade de vida no trabalho para os participantes da pesquisa está associada a variáveis organizacionais. A utilização do instrumento em versão digital facilitou o acesso e a aplicação em todas as agências, localizadas em diversas localidades brasileiras, permitindo o rápido tratamento dos dados.

A realização da pesquisa em um campo novo como as agências reguladoras, com características próprias, onde investigações e intervenções ainda são incipientes, propiciará um novo olhar para a melhoria do bem-estar dos trabalhadores desses órgãos de papel estratégico para o país. Ao oportunizar a construção desse novo cenário, possibilitar-se-á a promoção da cidadania aos trabalhadores, além da melhoria dos serviços prestados à sociedade.

Quanto às limitações do estudo, destaca-se que este, baseado em auto relato e que o fato de digitar a resposta ao invés de respondê-la verbalmente pode ter diminuído a quantidade e profundidade do conteúdo. Para o estabelecimento de uma agenda de pesquisa, sugerese a realização do microdiagnóstico, por meio da Análise Ergonômica do Trabalho, para aprofundamento das questões identificadas. Entende-se a importância de ampliar 
o campo de intervenção da pesquisa, realizando diagnóstico em outras agências, em empresas privadas e no terceiro setor, para compreensão, análise e comparação da QVT e da abordagem em outros modelos gerenciais.

É importante que a QVT seja compartilhada por todos na organização, sem deixar de ser, também, objetivo institucional, onde todos devem estar orientados na busca permanente de integrar bem-estar, eficiência e eficácia no trabalho. Cabe ressaltar, ainda, a necessidade do fortalecimento dos fatores/questões que aparecem como positivas no diagnóstico.

A QVT aqui proposta, de viés de promoção, permitirá a construção de um cenário onde ganham trabalhadores, agências reguladoras e por que não dizer, a sociedade brasileira.

Por fim, resgata-se um trecho do discurso de um respondente da instituição que afirmou: "A Agência está doente, mas tem cura, a depender dos seus líderes e colaboradores. Creio que tudo se resume em querer fazer e deixar fazer!". Essa é a QVT esperada pelos trabalhadores e que deve ser construída e consolidada por todos os atores organizacionais.

\section{Referências}

Abarqouei, N. S., \& Nasab, H. H. (2011). Total ergonomics and impact in muscoeskeletal disorders and quality of work life and productivity. Open Journal of Safety Science and Technology, 1, 79-88.

Abrahão, J., Sznelwar, L., Silvino, A., Sarmet, M., \& Pinho, D. (2009). Introdução à Ergonomia: Da prática à teoria. São Paulo: Editora Blucher.

Aketch, J. R., Odera, O., Chepkuto, P., \& Okaka, O. (2012). Effects of Quality of Work Life on Job Performance: Theoretical Perspectives and Literature Review. Journal of Social Sciences, 4(5), 383-388.

An, J., Hee, Y., \& Ruggiero, J. S. (2010). Organizational Culture, Quality of Work Life, and Organizational Effectiveness in Korean University Hospitals. Journal of Transcultural Nursing, 22(1), 22-30.

Andrade, P. P. (2011). Sentimento de (in)justiça na Justiça: Fatores (des) estruturantes de QVT sob a ótica dos servidores de um órgão do Poder Judiciário. Dissertação de Mestrado, Universidade de Brasília, Brasil.

Antloga, C. S. (2009). Práticas gerenciais e qualidade de vida no trabalho: O caso das micro e pequenas empresas do setor de serviços de alimentação em
Brasília. Tese de Doutorado, Universidade de Brasília, Brasil.

Araújo, T. M., Sena, I. P., Viana, M. A., \& Araújo, E. M. (2006). Mal-estar docente: Avaliação de condições de trabalho e saúde em uma instituição de ensino superior. Revista Baiana de Saúde Pública, 29(1), 6-21.

Aznar, M. P. M., Rodriguez, M. A. G., \& Aznar, M. J. M. (2006). Estrés y malestar en el profesorado. International Journal of Psychology and Psychological Therapy, 6(1), 63-76.

Bendassolli, P. (2011). Mal-estar no trabalho: Do sofrimento ao poder de agir. Revista Mal-estar e Subjetividade, 10(1), 63-98.

Bragard, I., Dupuis, G., Razavi, D., Reynaert, C., \& Etienne, A.M. (2012). Quality of work life in doctors working with cancer patients. Occupational Medicine, 62, 3440 .

Branquinho, N. G. S. (2010). Qualidade de vida no trabalho e vivencias de bem-estar e mal-estar no trabalho em professores da rede pública de ensino de Unaí/MG. Dissertação de Mestrado, Universidade de Brasília, Brasil.

Brunault, P., Fouquereau, E., Colombat, P., Gillet, N., El- Hage, W., Camus, V., \& Gaillard, P. (2013). Do transactive memory and participative teamwork improve nurses' quality of work life? Western Journal of Nursing Research, 36(3), 329-345.

Camargo, B. V. (2005). Alceste: um programa informático de análise quantitativa de dados textuais. In A. S. P. Moreira, B. V. Camargo, J. C. Jesuíno, \& S. M. Nóbrega (Orgs.), Perspectivas teórico-metodológicas em representações sociais. João Pessoa: Ed. Universitária UFPB.

Chávez, R. C. (2009). Condiciones de trabajo y bienestar/ malestar docente em profesores de enseñanza media de Santiago de Chile. Educação e Sociedade, 30(107), 409-426.

Feitosa, L. R. C. (2010). E se a orquestra desafinar? Contexto de produção e qualidade de vida no trabalho dos músicos da Orquestra Sinfônica de Teresina/PI. Dissertação de Mestrado, Universidade de Brasília, Brasil.

Fernandes, E. (1996). Qualidade de Vida no Trabalho: como medir para melhorar. Salvador: Casa da Qualidade. 
Fernandes, L. C. (2013). "Estamos o tempo todo enxugando gelo": Qualidade de vida no trabalho e vivências de bem-estar e mal-estar em um órgão do Poder Judiciário. Dissertação de Mestrado, Universidade de Brasília, Brasil.

Ferreira, M. C. (2003). O sujeito forja o ambiente, o ambiente forja o sujeito: Mediação indivíduo-ambiente em Ergonomia da Atividade. In M.C. Ferreira, \& S. Rosso (Org.), A regulação social do trabalho ( $1^{\mathrm{a}} \mathrm{ed}$., pp. 21-46). Brasília DF: Paralelo 15.

Ferreira, M. C. (2006). Ofurô Corporativo. Recuperado de http:/www.ergopublic.com.br/ arquivos/1256395632.59-arquivo.pdf.

Ferreira, M. C. (2008). A Ergonomia da atividade se interessa pela qualidade de vida no trabalho? Reflexões empíricas e teóricas. Cadernos de Psicologia Social e do Trabalho, 11, 83-99.

Ferreira, M. C. (2009). Inventário de Avaliação de Qualidade de Vida no Trabalho (IA_QVT): Instrumento de Diagnóstico e Monitoramento de QVT nas Organizações. Anais da $61^{a}$ Reunião da Sociedade Brasileira para o Progresso da Ciência. Manaus, AM, Brasil.

Ferreira, M. C. (2011a). Qualidade de Vida no Trabalho. In A. D. Cattani, \& L. Holzmann (Orgs.), Dicionário Trabalho e Tecnologia (2a ed., pp. 285-289). Porto Alegre: Editora Zouk.

Ferreira, M. C. (2011b). Qualidade de Vida no Trabalho. Uma Abordagem Centradano Olhardos Trabalhadores. Brasília: Edições Ler, Pensar, Agir (LPA).

Ferreira, M. C. (2011c). A ergonomia da atividade pode promover qualidade de vida no trabalho? Reflexões de natureza metodológica. Revista Psicologia: Organizações e Trabalho, 11 (1), 8-20.

Ferreira, M. C. (2012). Qualidade de Vida no Trabalho. Uma Abordagem Centrada no Olhar dos Trabalhadores $\left(2^{\mathrm{a}}\right.$ ed.). Brasília DF: Paralelo 15.

Ferreira, R.R., Ferreira, M. C., Antloga, C. S. X., \& Bergamaschi, A.V. (2009). Concepção e implantação de um programa de qualidade de vida no trabalho (PQVT) no setor público: O papel estratégico dos gestores. Revista de Administração (FEA-USP), 44, 147-157.

Ferreira, M. C., \& Mendes, A. M. (2003). Trabalho e riscos de adoecimento: O caso dos auditores-fiscais da Previdência Social Brasileira. Brasília: Edições Ler, Pensar, Agir (LPA).

Ferreira, M. C., \& Seidl, J. (2009). Mal-estar no trabalho: análise da cultura Organizacional de um contexto bancário brasileiro. Revista Psicologia: Teoria e Pesquisa, Brasilia, 25(2), 245-254.

Ferreira, M. C., Alves, L., \& Tostes, N. (2009). Gestão de qualidade de vida no trabalho (QVT) no serviço público federal: o descompasso entre problemas e práticas gerenciais. Psicologia: Teoria e Pesquisa, 25, 319-327.

Figueira, T. G. (2014). Bem-Estar, Mal-Estar e Qualidade de Vida no Trabalho em uma Instituição Pública Brasileira. Tese de Doutorado, Universidade de Brasília, Brasil.

Fonseca, L. M. (2010). Termos e expressões utilizados por familiares ao relatarem suas experiências nos diferentes momentos do adoecimento mental. Dissertação de Mestrado, Universidade de São Paulo, Ribeirão Preto, SP, Brasil.

Huang, T. C., Lawler, J., \& Lei, C. Y. (2007). The effects of quality of work life on commitment and turnover intention. Social Behavior and Personality, 35(6), 735750 .

Josiah, R. A., Odera, O., Chepkuto, P., \& Okaka, O. (2012). Effects of quality of work life on job performance: theoretical perspectives and literature review. Current Research Journal of Social Science, 4(5), 383-388.

Koonmeee, K., Singhapakdi, A., Virakul, B., \& Lee, D. J. (2010). Ethics institutionalization, quality of work life, and employee job-related outcomes: a survey of human resource managers in Thailand. Journal of Business Research, 63, 20-26.

Lacaz, F. A. C. (2000). Qualidade de vida no trabalho e saúde/doença. Ciência \& Saúde Coletiva, 5(1), 151161.

Lawler, E. E. (1982). Strategies for improving the quality of work life. American Psychologist, 37(5), 486-493.

Lee, Ya-Wen, Dai, Yu-Tzu, Park, Chang-Gi, \& McCrearyl, L. L. (2013). Predicting Quality of Work Life on Nurses' Intention to Leave. Journal of Nursing Scholarship, 45(2), 160-168.

Li, J., \& Yeo, R. K. (2011). Quality of work life and career 
development: perceptions of part-time MBA students. Employee Relations, 33(3), 201-220.

Maciel, R. H., Sena, F. C., \& Saboia, I. B. (2006). O mal-estar nas novas formas de trabalho: um estudo sobre a percepção do papel dos cooperados em uma cooperativa de trabalho autogestionário. Revista MalEstar e Subjetividade, 6(2), 535-560.

Maia, M. (2014). “Tribunal da cidadania?! Pra quem?!: Qualidade de vida no trabalho em um órgão do Poder Judiciário brasileiro. Dissertação de Mestrado, Universidade de Brasília, Brasil.

Marta, J. K. M., Singhapakdi, A., Lee, D. J., Sirgy, M. J., Koonmee, K., \& Virakul, B. (2013). Perceptions about ethics institutionalization and quality of work life: Thai versus American marketing managers. Journal of Business Research, 66, 381-389.

Martel, J. P., \& Dupuis, G. (2006). Quality of work life: theoretical and methodological problems, and presentation of a new model and measuring instrument. Social Indication Researche, 77, 333-368.

Nadler, D. A., \& Lawler, E. E. (1983). Quality of work life: perspectives and directions. Organizational Dinamics, 11(3), 20-30.

Nayeri, N. D., Salehi, T., \& Noghabi, A. A. A. (2011). Quality of work life and productivity among Iranian nurses. Contemporary Nurse, 39(1), 106-118.

Oliveira Filho, G. J. (2005). Desenho regulatório e competitividade: efeitos sobre os setores de infraestrutura [Relatório de Pesquisa/2005]. São Paulo, SP: Fundação Getúlio Vargas.

Oliveira Filho, G. J., Fujiwara, T., \& Machado, E. L. A (2005). A experiência brasileira com agências reguladoras. In L. H. Salgado, \& R. S. Motta (Orgs.), Marcos regulatórios no Brasil: o que foi feito e o que falta fazer (Vol. 1, pp. 163-197). Rio de Janeiro: IPEA.

Pacheco, R. S. (2006). Regulação no Brasil: desenho das agências e formas de controle. Revista de Administração Pública (RAP), 40 (4), 523-43.

Paschoal, T., \& Tamayo, A. (2008). Construção e validação da escala de bem-estar no trabalho. Avaliação Psicológica, 7(1), 11-22.

Paschoal, T., Torres, C. V., \& Porto, J. B. (2010). Felicidade no trabalho: relações com suporte organizacional e suporte social. Revista de Administração Contemporânea (RAC), 14(6), 1054-1072.

Pó, M. V., \& Abrucio, F. L. (2006). Desenho e funcionamento dos mecanismos de controle e accountability das agências reguladoras brasileiras: semelhanças e diferenças. Revista de Administração Pública (RAP), Rio de Janeiro 40(4), 679-98.

Reinert, M. (1990). Alceste, une méthodologie d'analyse des dones textuelles et une application. Bulletin de Methodologie Sociologique, 28, 23-32.

Ribeiro, A. S. M. (2009). Alceste: Análise quantitativa de dados textuais [Manual]. Brasília: Universidade de Brasília.

Sampaio, J. R. (2012). Qualidade de vida no trabalho: perspectivas e desafios atuais. Revista Psicologia Organizacional e Trabalho, 12(1), 121-136.

Silva, N. (2005). O mal-estar da professora alfabetizadora: contribuições de D. Winnicot. Revista Mal-Estar e Subjetividade, 5(1), 11-44.

Siqueira, M. M. M., \& Padovam, V. A. R. (2008). Bases teóricas de bem-estar subjetivo, bem-estar psicológico e bem-estar no trabalho. Psicologia: Teoria e Pesquisa, 24(2), 201-209.

Sirgy, M. J., Efraty, D., Siegel, P., \& Lee, D. (2001). A New Measure of Quality of Work Life (QWL) Based on Need Satisfaction and Spillover Theories. Social Indicators Research, 55(3), 241-302.

Sirgy, M. J., Reilly, N. P., Wu, J., \& Efraty, D. (2008). A work-life identifty model of well-being: towards a research agenda linking quality-of-work-life (QWL) programs with quality of life (QOL). Applied Research in Quality of Life, 3(3), 181-202.

Tavares, D. S. (2003). O sofrimento no trabalho entre servidores públicos: Uma análise psicossocial do contexto de trabalho em um tribunal judiciário federal. Dissertação de Mestrado, Universidade de São Paulo, Brasil.

Tolfo, S. R., Silva, N., \& Luna, I. N. (2009). Cultura organizacional, identidade e qualidade de vida no trabalho: articulações e sugestões de pesquisas em organizações. Pesquisas e práticas psicossociais, 4(1), 6-16.

Veras, V. S., \& Ferreira, M. C. (2006). "Lidar com gente 
é muito complicado": relações socioprofissionais de trabalho e custo humano da atividade em tele atendimento governamental. Revista Brasileira de Saúde Ocupacional, 114(31), 135-148.

Zhao, X. W., Sun, T., Cao, Q., Li, C., Duan, X., Fan, L., \& Liu, Y. (2012). The impact of quality of work life on job embeddedness and affective commitment and their co-effect on turnover intention of nurses. Journal of Clinical Nursing, 22, 780-788.

\section{Endereço para correspondência:}

Veruska Albuquerque Endereço: Universidade de Brasília, Instituto de Psicologia, Campus Universitário Darcy Ribeiro, ICC Sul, Caixa Postal 4500, Asa Norte. Brasília-DF, CEP: 7.910900.

E-mail: albuquerque.veruska@gmail.com

\section{Endereço para correspondência:}

Mário César Ferreira

Endereço: Universidade de Brasília, Instituto de

Psicologia, Campus Universitário Darcy Ribeiro, ICC Sul, Caixa Postal 4500, Asa Norte. Brasília-DF, CEP: 7.910900.

E-mail: mcesar@unb.br

\section{Endereço para correspondência:}

Carla Antloga

Endereço: Universidade de Brasília, Instituto de

Psicologia, Campus Universitário Darcy Ribeiro, ICC Sul, Caixa Postal 4500, Asa Norte. Brasília-DF, CEP: 7.910900.

E-mail: antlogacarla@gmail.com

\section{Endereço para correspondência:}

Marina Maia

Endereço: Universidade de Brasília, Instituto de Psicologia, Campus Universitário Darcy Ribeiro, ICC Sul, Caixa Postal 4500, Asa Norte. Brasília-DF, CEP: 7.910900.

E-mail:m.maiacarmo@gmail.com 